\section{EMBRYRIDDLE}

Aeronautical University

SCHOLARLY COMMONS
Journal of Aviation/Aerospace Education \& Research

Volume 11

Number 2 JAAER Winter 2002

Article 5

Winter 2000

\title{
General Aviation Landing Flare Instructions
}

Danny Benbassat

Charles J. Abramson

Follow this and additional works at: https://commons.erau.edu/jaaer

\section{Scholarly Commons Citation}

Benbassat, D., \& Abramson, C. J. (2000). General Aviation Landing Flare Instructions. Journal of Aviation/ Aerospace Education \& Research, 11(2). https://doi.org/10.15394/jaaer.2002.1298

This Article is brought to you for free and open access by the Journals at Scholarly Commons. It has been accepted for inclusion in Journal of Aviation/Aerospace Education \& Research by an authorized administrator of Scholarly Commons. For more information, please contact commons@erau.edu. 


\title{
GENERAL AVLATION LANDING FLARE INSTRUCTIONS
}

\author{
Danny Benbassat and Charles I. Abramson
}

\begin{abstract}
The present paper discusses the ability to determine low altitudes and challenges the effectiveness of current general aviation landing flare instructions. Conclusions are based on literary review from a variety of sources such as general aviation flight instruction manuals, aviation literature, and scientific publications. Key findings suggest that current flare instructions are inconsistent, ambiguous, and of limited helpfulness to pilots wishing to learn how to determine altitude before initiating the landing flare.
\end{abstract}

\section{General Aviation Landing Flare Instructions}

The transition from a controlled descent to actual contact with the runway surface is known as the flare, roundout, leveloff, or flareout and is a special maneuver within the landing phase of operation (Jeppesen, 1985). Successful flares are essential to smooth and safe landings (Grosz et al., 1995; King, 1999) and are frequently used to evaluate pilot performance (Collins, 1981; King, 1998). Hence, the consequences of improper flares are far reaching and include both the physical integrity of the aircraft (see Christy, 1991; Jorgensen, \& Schley, 1990) and the mental efficacy of the pilot (see Collins, 1981; King, 1998; Matson, 1973). The purpose of this paper is to evaluate the effectiveness of current flare instructions as documented in the literature.

The ability to determine the aircraft altitude is critical to a successful flare (Love, 1995) and may distinguish between a proper and improper flare. The flare is tantamount to braking an automobile with the purpose of preventing a collision with a wall (Grosz et al., 1995). Whereas braking too late would result in an unpleasant impact, braking too early would stop the automobile before reaching the wall. Similarly, flaring an aircraft too late (see Christy, 1991; Jeppesen, 1985; Kershner, 1981; Kershner, 1998; Love, 1995) may result in an unpleasant impact with the runway surface (Federal Aviation Administration, Revised 1999), bouncing (Kershner, 1998), or a "wheelbarrow" landing (Butcher, 1996; Love, 1995). Conversely, flaring too early (see Christy, 1991; Gleim, 1998; Jeppesen, 1985; Kershner, 1998; King, 1999; Quinlan, 1999) will not stop the aircraft in midair, but will lead to a stall and a hard landing (Federal Aviation
Administration, Revised 1999).

Recognizing the mechanism by which pilots determine the aircraft altitude Above Ground Level (AGL) is paramount to the success of any flare instruction. According to the title 14 Code of Federal Regulations (CFR), altimeter tolerance is set at $9.14 \mathrm{~m}(30 \mathrm{ft})$, but it is not uncommon for General Aviation (GA) altimeters to be off by as much as $22.86 \mathrm{~m}$ $(75 \mathrm{ft})$. Apparently, GA pilots that initiate the flare 3.05 $6.10 \mathrm{~m} \mathrm{(10} \mathrm{-} 20 \mathrm{ft})$ AGL cannot rely on the altimeter and must resort to alternative cues. Such cues consist of ground effect, time-to-contact (see Grosz et al., 1995; Mulder, Pleijsant, van der Vaart, \& van Wieringen, 2000), and kinesthetic information (Jeppesen, 1985; Menon, 1996). Nevertheless, it appears that pilots use vision more than any other tool to determine their altitude during the flare (Federal Aviation Administration, Revised 1999; Green, Muir, James, Gradwell, \& Green, 1996; Jeppesen, 1985; Thom 1992).

In particular, pilots rely on monocular rather than binocular vision during the approach, landing, and flare (Benson, 1999; Bond, Bryan, Rigney, \& Warren, 1962). An in-depth discussion of binocular and monocular vision is beyond the scope of this paper. Nevertheless, a distinction between the two is vital to the discrimination between effective and ineffective flare instructions.

Binocular (bi=two, ocular=eye) vision combines sensory information from both eyes. The disparate visual signals from each eye are fused to produce threedimensional depth perceptions (see Goldstein, 1980). Fusion is also known as stereopsis and is thought of as "pure" three-dimensional vision. As Table 1 shows, the two other binocular cues are accommodation and convergence. 
Unlike binocular vision, monocular (mono $=$ one, ocular=eye) vision does not require the use of both eyes (see Benson, 1999; Bond et al., 1962; Green, 1988; Kershner, 1981; Langewiesche, 1972; Peter, 1999; Reinhart, 1996; Reinhardt-Rutland, 1997; Riordan, 1974; Tredici, 1996), and generates depth perception from a two-dimensional environment (Hawkins, 1993; for an example see Nagel, 1988). The ability to generate depth perception from a two dimensional environment depends on perceptual cues which we will refer to as "monocular cues". Exemplars of monocular cues are presented in Table 2 along with concise descriptions.

At this stage it would be appropriate to consider fundamental differences between binocular and monocular vision. First, binocular depth perception may be an innate ability and certainly exists at a very early age

\section{Table 1}

\section{Binocular Cues}

1. Accommodation. The lenses protrude for close and flatten for distant objects.

2. Convergence. The eyes move inward for close and outward for distant objects.

3. Stereopsis. The fusion of signals from slightly disparate retinal points that result in a visual appreciation of three dimensions.

(Reading, 1983; also see Fox, Aslin, Shea, \& Dumais, 1980; Kalat, 1998; Reinecke \& Simons, 1974). On the other hand, monocular depth perception is an acquired ability that must be learned through experience (Benson, 1999; Bramson, 1982; Langewiesche, 1972; Love, 1995; Marieb,1995; Tredici, 1996). Thus, the first distinction between binocular and monocular vision is akin to that of nature vs nurture and is of significance to landing flare instructions. Another principal distinction between binocular and monocular vision is operational range. Unlike monocular vision, binocular vision has a restricted range and is only dependable for short distances (Green, 1988; Langewiesche, 1972; Reinhardt-Rutland, 1997; Reinhart, 1982; Reinhart, 1996). For example, some birds have visual pathways that are specialized for binocular and monocular vision (Güntürkün, Miceli, \& Watanabe, 1993). The tendency to alternate between the two pathways depends on the visual task at hand. Pigeons, eagles, and falcons use monocular vision to search for distant food or enemies, but switch to binocular vision to fixate on close objects when approaching a prey or pecking. This fundamental distinction negates the popular notion that pilots use stereoscopic vision during the landing phase of operation (Langewiesche, 1972), and stresses the importance of monocular cues during the flare. 
Table 2

Monocular Cues

1. Aerial perspective - distant objects appear more bluish and hazy than do near objects.

2. Illumination perspective - light sources are assumed to be from above.

3. Interposition - closer objects obscure distant objects from vision.

4. Linear perspective - parallel lines seem to converge with distance.

5. Motion parallax - the relative motion of images across the retina. Nearer objects appear to move faster than distant objects.

6. Relative height - objects that appear higher in the visual field appear more distant than lower objects.

7. Relative size - larger objects seem to appear closer than distant objects.

8. Shadow - closer objects usually cast shorter shadows than distant objects.

9. Texture gradient - detail is lost with increasing distance. 
Reliance on binocular cues may actually discourage pilots from acquiring the necessary skills for depth perception during the flare. For example, Liebermann and Goodman (1991) examined the effects of visual information on the ability to reduce impacts at touchdown from four height categories ranging from $5-95 \mathrm{~cm}(0.16-3.12 \mathrm{ft})$. To generate landing impacts, a horizontal free-fall device with a self-releasing mechanism was used. Participants were randomly assigned to vision and no-vision conditions. Participants in the no vision condition were allowed to see the height from which they would release themselves, as well as the landing' surface prior to the free-fall. Liebermann and Goodman discovered that vision during flight did not aid participants in producing softer landings at touchdown. In fact, under certain conditions, higher impacts were registered when vision was available. Thus, Leibermann and Goodman concluded that two-dimensional recollections might have had an advantage over continuous visual guidance.

The contribution of monocular cues to smooth and safe landings led to a plethora of studies that isolated crucial cues. Frequent monocular cues that pilots use to determine altitude during the flare are presented in Figure 1. Nevertheless, it seems that pilots use different cues or combination of monocular cues and any attempt to determine the superiority of one cue over another is futile (Benbassat \& Abramson, in press; Bond et al., 1962; Green, 1988; Riordan, 1974; Tiffin \& Bromer, 1943; Warren \& Owen, 1982). Moreover, it seems that awareness is not critical to the learning of monocular cues, and that pilots cannot explain how they use vision to determine altitude during the flare (Benbassat \& Abramson, in press; Berbaum, Kennedy, \& Hettinger, 1991). These predicaments are reflected in current flare instructions. Overall, traditional flare instructions are inconsistent and ambiguous, and a review of the literature suggested that one flare instruction was not better than another.

In reference to the flare maneuver, the Airplane

Flying Handbook (Federal Aviation Administration, Revised 1999) states that the flare should be started within "what appear to be" (p. 7-6) $3.05-6.10 \mathrm{~m}$ (10 - $20 \mathrm{ft}$ ) above the ground. Nevertheless, the handbook does not instruct pilots how to determine what "appears to be" the appropriate altitude, and what

seems to one as a reasonable flare altitude may seem "ridiculous" to

another (Bramson, 1982, p. 44). Certified Flight Instructors
(CFIs) may also provide ambiguous instructions. Instructing pilots to initiate the flare at the height of a double decker bus (Bramson, 1982), hangar height (Kershner, 1998), or one-half of the aircraft wingspan (Christy, 1991) may prove difficult. Not everyone is familiar with a double deck bus, hangars may appear different or not be present at all, and using the wingspan as a measurement scale is a complicated visual-spatial task. Regretfully, some instructors never really try to explain how to determine flare altitude and resolve to comment such as "just about now begin to flare" or "you're too high!" which only increases the frustration of not knowing when to initiate the flare (Bramson, 1982; Penglis, 1994).

Attempts to design alternative flare training instructions have only met with partial success. One such attempt suggested prolonged flares (Bramson, 1982; Kershner, 1981) or flying the aircraft at flare altitude down the runway. Prolonged flares were presumed to improve scanning techniques and allow pilots to appreciate the visual environment at flare altitude. Matson (1973) examined the effectiveness of prolonged flares as a teaching tool. He investigated the effects of prolonged flares on (a) attempts to land, (b) time-to-land, and (c) time to solo across instructional environments (i.e., aircraft type, instructors, and sequence of maneuvers).

No significant differences were found among the students taught by the

prolonged flares and those taught by traditional flare methods.

Another attempt incorporated a visual illusion prevalent during the flare (Penglis, 1994; also see Dempsey, 1993; Fowler, 1984). Throughout a normal approach the aircraft appears to be descending towards the ground, but as the aircraft transitions for landing the ground appears to rise toward the aircraft. Pilots should initiate the flare when the ground appears to rise and the nose of the aircraft is at level attitude with the far end of the runway. Placing the nose of the aircraft just under the end of the runway will compel pilots that tend to flare too high to continue their descent until they are able to place the nose just under the runway end. Conversely, pilots that flare too late will be required to initiate the flare earlier in order to achieve the desired visual reference. Nevertheless, a review of the literature and anecdotal evidence did not provide a critical evaluation of this method.

Regretfully, the flare is acknowledged as one of the most difficult maneuvers (Barnhart, as cited in Matson, 
1973; Benbassat \& Abramson, in press; Langewiesche, 1972; Love, 1995; Penglis, 1994) and landing flare accidents are relatively frequent (Benbassat \& Abramson, in press). Yet, landing flare studies are sporadic and the contribution of proper flares to successful landings is traditionally ignored in the literature and aviation safety proceedings. Perhaps that is why "the one phase that can cause the majority of student pilots to question why they took up flying (and make their instructors wish they had stuck to golf) is the transition from approaching down the gentle glide path to that brief flit over the runway. ..." (Bramson, 1982, p. 44).

\section{DISCUSSION}

Understanding how pilots determine altitude during the flare is paramount to the success of flare instructions. The contribution of monocular vision to smooth and safe landings dictates potential limitations in traditional flare instructions. Unlike binocular cues, monocular cues must be learned through experience and evidence suggests that the ability to determine altitude improves with experience (Rinalducci, Patterson, Forren, \& Andes, 1985; Tredici, 1996). Nevertheless, the one thing that most student and GA pilots lack is experience. On average, the flare only lasts $6 \mathrm{sec}$ and a $5000 \mathrm{hrs}$ pilot only has about 8 hrs of flare time (King, 1998).

Experienced CFIs entrusted with flare instructions are confronted with a hurdle of a different kind. It seems that awareness is not critical to the learning of monocular cues and most pilots cannot explain how they use vision to determine their altitude during the flare. Is it possible to expect flight instructors to explain what they themselves do not know (Benbassat \& Abramson, in press; Penglis, 1994)? Ambiguity is not restricted to 'where to look', but also extends to 'how to look'. Traditional flare instructions recommend looking as far ahead as if one were driving a car at the same speed (Christy, 1991), but it is possible that since drivers tend to look too far ahead and are not required to determine altitude, pilots will flare too late (Grosz, et al., 1995; Kershner, 1981). Flare instructions are especially difficult since pilots use different cues or combinations of monocular cues. Nevertheless, the differential use of monocular cues allow pilots to execute appropriate flares at different airports with different visual environments. In other words, the "cocktail" of monocular cues allow pilots to determine altitude AGL even in unfamiliar airports that lack key monocular cues such as familiar objects.

In conclusion, a review of the literature suggests that flare instructions are not consistent and that no one method is better than another (also see Matson, 1973). Perhaps that is why 'the reason no student knows where the ground begins is because the method we use to teach landings to students is wrong and does not work" (Penglis, 1994, p. 91). Alternative flare instructions that challenge shortcomings addressed in this paper are desired. Of special interest are standardized behavioral flare instructions that would facilitate the association between proper flare altitude and appropriate cues in the airport environment.

Thus, our laboratory research is currently directed towards the development of an automated flare beacon. The beacon alerts the pilot when s/he approaches the ideal flare altitude in a consistent and accurate manner. It is proposed that such a beacon will reduce CFI workload and eliminate the need to explain what CFIs themselves do not know. As a final point, instead of learning to determine altitude $A G L$ in a trial-and-error fashion, the flare beacon is anticipated to enable pilots to discriminate cues or combination of depth perception cues thereby addressing the issue of inexperience. $\square$

Danny Benbassat received his M.A. from Slippery Rock University of Pennsylvania and his M.S. from Oklahoma State University. He anticipates receiving his Ph.D. in the summer of 2002 from Oklahoma Sate University. He is a member of the aviation community and has been actively involved in the study of general aviation landing flares over the past two years.

Charles Abramson, Ph.D., is the author of over 40 research articles, 90 abstracts, and 5 books and is considered an expert in the areas of behavior analysis and training. He is also the coordinator of the Oklahoma State University program in Experimental Psychology. 


\section{REFERENCES}

Benbassat, D., \& Abramson, I. C. (in press). Landing flare accident reports and pilot perception analysis. International Journal of Aviation Psychology.

Benson, A. J. (1999). Spatial disorientation -- general aspects. In J. Ernsting, A. N. Nicholson, \& D. J. Rainford (Eds.). Aviation medicine (3rd ed.) (pp. 419 - 454). Butterworth Heinemann: Jordan Hill, Oxford, Great Britain.

Berbaum, K. S., Kennedy, R. S., \& Hettinger, L. J. (1991). Visual tasks in helicopter shipboard landing. Applied Ergonomics, 22, 231-239.

Bond, N. A., Bryan, L. G., Rigney, J. W., \& Warren, N. D. (1962).Aviation psychology (aero - space science series). Aviation and Missile Safety Division: University of Southern California, Los Angeles, CA.

Bramson, A. (1982). Make better landings. Van Nostrand Reinhold: New York, NY.

Butcher, R. (1996). Private pilot flight training manual. Skyroamers: Orange, CA.

Christy, J. (1991). Good takeoffs and good landings (2nd ed.). Tab Books: Blue Ridge Summit, PA.

Collins, L. (1981). Takeoffs and landings. Delacorte Press / Eleanor Friede: New York, NY.

Dempsey, M. (1993). Biennial flight review. Professional Press:Chapel Hill, NC.

Federal Aviation Administration (Revised 1999). Airplane flying handbook (FAA -H - 8083 - 3). U.S Department of Transportation: Washington, DC.

Fox, R, Aslin, R N., Shea, S. L., \& Dumais, S. T. (1980). Stereopsis in human infants. Science, 207, 323-324.

Fowler, R. (1984). Making perfect landings. The Iowa State University Press: Ames, Iowa.

Gleim, I. N. (1998). Flight / ground instructor (6th ed.). Gleim Publication: Gainesville, FL.

Goldstein, E. B. (1980). Sensation and perception. Wadsworth: Belmont, CA.

Green, R. G. (1988). Perception. In J. Ernsting, \& P. King (Eds.). Aviation medicine (2nd ed.) (pp. 391 - 401). Butterworth Heinemann: Cambridge, Great Britain.

Green, R. G., Muir, H., James, M., Gradwell, D., \& Green, R. L. (1996). Human factors for pilots (2nd ed.). Avebury Aviation: Hampshire, England

Grosz J., Rysdyk, R, Bootsma, R. J., Mulder, J. A., Van der Vaart, J. C., \& Van Wieringen, P. W. (1995). Perceptual support for timing of the lare in the landing of an aircraft. In P. Hancock, J. Flach, J. Caird \& K.Vicente (Eds). Local applications of the ecological approach to human-machine systems. Lawrence Erlbaum Associates: Hillsdale, NJ.

Güntürkün, O., Miceli, D., \& Watanabe, M. (1993). Anatomy of the avian thalamofugal pathway. In P. H. Zeigler, \& H. Bischof (Eds.). Vision, brain, and behavior in birds. MIT: Cambridge, MA.

Hawkins, F. H. (1993). Human factors in flight (2nd ed.). Ashgate:Brookfield, Vermont.

Jeppesen (1985). Private pilot maneuvers manual. Jeppesen Sanderson: Englewood, CO.

Jorgensen, C. C., \& Schley, C. (1990). A neural network baselineproblem for control of aircraft flare and touchdown.

In M. W. Miller, \& R. S. Sutton (Eds.). Neural networks for control (pp. 403 - 425). MIT Press: Cambridge, MA.

Kalat, J. W. (1998). Biological psychology. Brooks / Cole: Pacific Grove: CA.

Kershner, W. K. (1981). The flight instructor's manual (2nd ed.). Iowa State University Press: Ames, Iowa.

Kershner, W. K. (1998). The student pilot's flight manual (8th ed.). Iowa State University Press: Ames, Iowa.

King (Producer). (1998). Takeoffs and landings made easy [Film]. (Available from King Schools: 3840 Calle Fortunada, San Diego, CA 92123)

King (Producer). (1999). Cleared for Takeoff - Cessna Private Pilot. [CD-ROM]. King Schools: San Diego, CA. Langewiesche, W. (1972). Stick and rudder. McGraw Hill: New York, NY.

Liebermann, D. G., \& Goodman, D. (1991). Effects of visual guidance on the reduction of impacts during

landings. Ergonomics, 34, (11), 1399-1406.

Love, M. C. (1995). Better takeoffs \& landings. Tab Books /McGraw - Hill: Colunbus, OH.

Menon, P. K. (1996). Machine-vision aids for improved flight operations. NASA: CA. 
Matson, W. R. (1973). The comparative effectiveness of a prolonged flare and normal flare on student pilot achievement in the landing maneuver and on time to solo. Unpublished doctoral dissertation, Oklahoma State University, Stillwater.

Marieb, E. N., (1995). Human anatomy and physiology (3rd ed.). Benjamin / Cumming Publishing Company: Redwood City, CA.

Mulder, M., Pleijsant, J., van der Vaart, H., \& van Wieringen, P. (2000). The Effects of pictorial detail on the timing of the landing flare: Results of a visual simulation experiment. International Journal of Aviation Psychology, 10, 291 -315 .

Nagel (1988). Human error in aviation operations. In E. L. Wiener,\& D. C. Nagel (Eds.). Human factors in aviation (pp. 263 - 303). Academic Press: San Diego: CA.

Penglis, G. M. (1994). The complete guide to flight instruction. Rainbows Books: Highland City, FL.

Peter, A. S. (1999). Vision in aviation. In J. Ernsting, A. N. Nicholson, \& D. J. Rainford (Eds.). Aviation medicine (3rd ed.) (pp. 472 - 488). Butterworth Heinemann: Jordan Hill, Oxford, Great Britain.

Quinlan, E. (1999). Recreational airplane pilot. Aviator Publisher:Oak Brook, IL.

Reading, R. W. (1983). Binocular vision: Foundations and applications. Butterworth Publishers: Woburn, MA.

Reinhardt - Rutland, A. H. (1997). Depth perception: A possible role for pictorial information in aviation. In Jensen, R. S. \& Rakovan, L. A. (Eds.). Ninth international symposium on aviation psychology (vol. 2). (pp. 1525 - 1529). Ohio State University: Columbus, $\mathrm{OH}$.

Reinecke, R D., \& Simons, K. (1974). A new stereoscopic test for amblyopia screening. American Journal of Ophthalmology, 78, 714-721.

Reinhart, R. O. (1982). The pilot's manual of medical certification and health maintenance. Specialty Press: Osceola, Wisconsin.

Reinhart, R. O. (1996). Basic flight physiology (2nd ed.). McGraw -Hill: New York, NY.

Rinalducci, E. J., Patterson, M. J., Forren, M., \& Andes, R. (1985). Altitude estimation of pilot and non-pilot observers using real-world scenes. In Jensen, R. S., \& Adrion, J. (Eds). The third symposium on aviation psychology (pp. 491 - 498). Ohio State University: $\mathrm{OH}$.

Riordan, R. H. (1974). Monocular visual cues and space perception during the approach and landing. Aerospace medicine, $45,766-771$.

Thom, T. (1992). The pilot's manual flight training. Center for Aviation Theory: Frederick, MD.

Tiffin, J., \& Bromer, J. (1943). Analysis of eve fixations and patterns of eye movement in landing a piper cub J - 3 airplane. Washington, D. C.:CAA Division of Research Report No. 14, April, 1943.

Tredici, T. J. (1996). Ophthalmology in aerospace medicine. In R. L. DeHart (Ed.) Fundamentals of aerospace medicine (2nd ed.) (pp. 519 - 566). Williams \& Wilkins: Baltimore, MD.

Warren, R., \& Owen, D. H. (1982). Functional optical invariants: A new methodology for aviation research. Aviation, Space, and Environmental Medicine, 53, 977 - 983.

\section{AUTHOR NOTE}

Funding for this paper was made possible through a grant from The Wolf Aviation Fund. Special thanks to Kevin Williams, Ph.D. of the Federal Aviation Administration Civil Aeromedical Institute for his previous edits. 


\section{Figure Caption}

Figure 1. Monocular cues frequently used to determine altitude Above Ground Level during the landing flare (Benbassat \& Abramson, in press; also see Langewiesche, 1972; Riordan, 1974; Tredici, 1996).

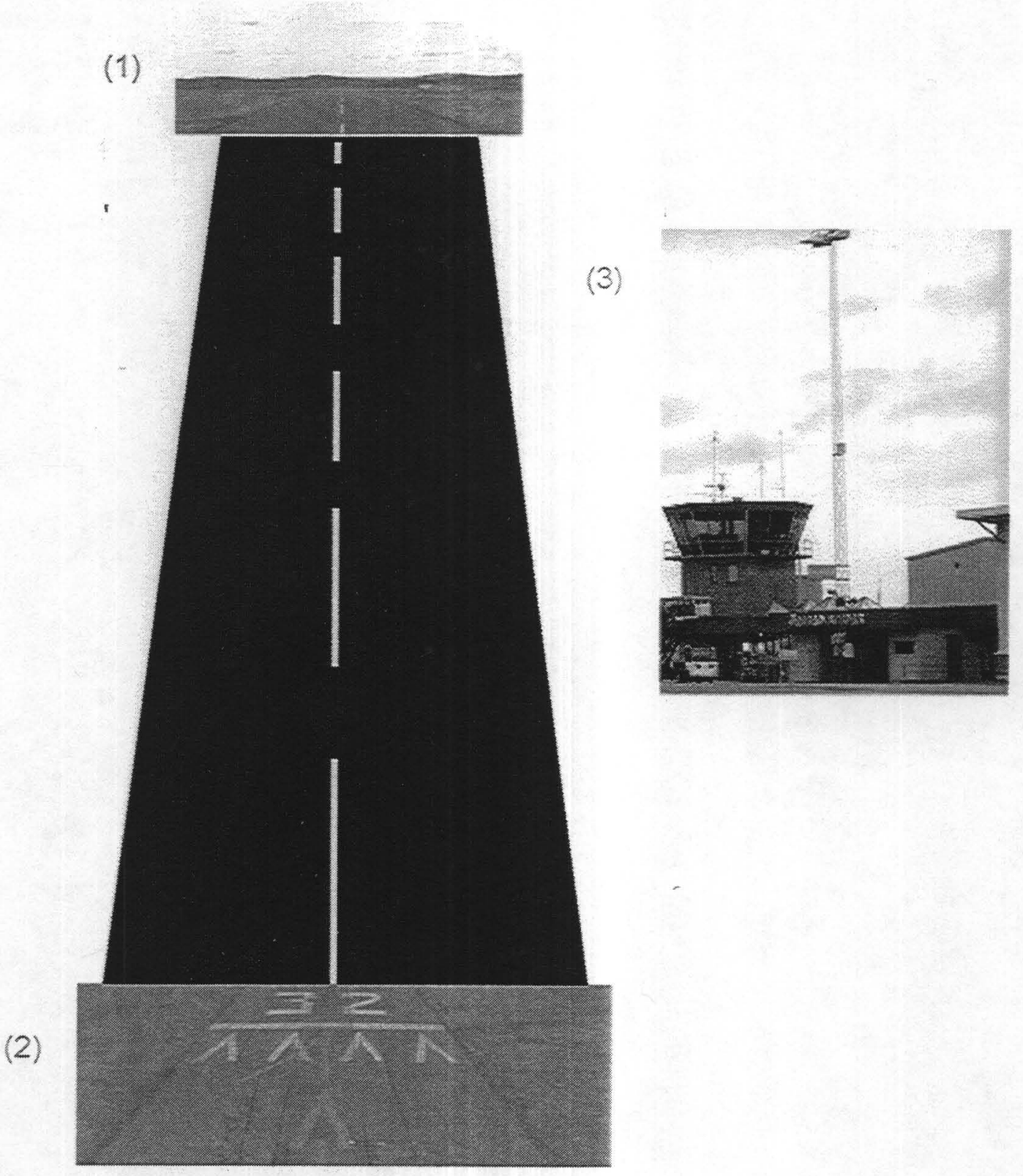

(1) horizon / end of runway

(2) shape of runway / runway markings

(3) familiar objects / size of retinal image 